\title{
Investigation of Atmospheric Turbidity at Ghadaa (Algeria) Using Both Ground Solar Irradiance Measurements and Space Data
}

\author{
Djafer Djelloul1*', Irbah Abdanour², Keckhut Philippe², Zaiani Mohamed', Meftah Mustapha² \\ ${ }^{1}$ Unité de Recherche Appliquée en Energies Renouvelables, URAER, Centre de Dèvellopement des Energies Renouvelables, CDER, \\ Ghardaïa, Algeria \\ ${ }^{2}$ LATMOS/IPSL, UVSQ Université Paris-Saclay, Sorbonne Université, CNRS, Guyancourt, France \\ Email: *djafer.djelloul@uraer.dz
}

How to cite this paper: Djelloul, D., Abdanour, I., Philippe, K., Mohamed, Z. and Mustapha, M. (2019) Investigation of Atmospheric Turbidity at Ghadaa (Algeria) Using Both Ground Solar Irradiance Measurements and Space Data. Atmospheric and Climate Sciences, 9, 114-134.

https://doi.org/10.4236/acs.2019.91008

Received: January 4, 2018

Accepted: January 5, 2019

Published: January 8, 2019

Copyright (ㅇ 2019 by authors and Scientific Research Publishing Inc. This work is licensed under the Creative Commons Attribution International License (CC BY 4.0).

http://creativecommons.org/licenses/by/4.0/

\begin{abstract}
Four radiometric models are compared to study the Angström turbidity coefficient $\beta$ over Ghardaïa (Algeria). Five years of global irradiance measurements and space data recorded with MODIS are used to estimate $\beta$. The models are referenced as $\beta_{\text {Dog }}$ for Dogniaux's method, $\beta_{\text {Louch }}$ for Louche's method, $\beta_{\text {Pinz }}$ for Pinazo's method, $\beta_{\text {Gyem }}$ for Gueymard's method and by $\beta_{\text {modis }}$ for MODIS data. The results showed that $\beta_{\text {Gyem }}$ and $\beta_{\text {Pinz }}$ are very close as the couple $\beta_{D o g}$ and $\beta_{\text {modis }}$. $\beta_{\text {Louch }}$ values are between them. Results showed also that all Angström coefficient curves have the same annual trend with maximum and minimum values respectively in summer and winter months. Annual mean values of $\beta$ increased from 2005 to 2008 with a slight jump in 2007 except for $\beta_{\text {Louch }}$. The city environment explains it since the urban aerosols predominate over all other types during this period. The jump in 2007 is attributed to the ozone layer thickness that undergoes the same behavior. Some models are then more sensitive to this atmospheric component than others. The occurrence frequency distribution showed that $\beta_{\text {Dog }}, \beta_{\text {Louch }}, \beta_{\text {Pinz }}, \beta_{\text {Gyem }}$ and $\beta_{\text {modis }}$ had their maximum recurrent values near $0.03,0.07,0.10,0.09$ and 0.02 respectively. The cumulative frequency distribution revealed also that $\beta_{\text {Dog }}$ and $\beta_{\text {modis }}$ yielded maximum "clean to clear" conditions with respect to others while $\beta_{\text {Pinz }}$ and $\beta_{\text {Gyem }}$ had the minimum. The opposite was observed on the same $\beta$ pairs with regard to "clear to turbid" and "turbid to very turbid" conditions. Louche's model gave middle values of sky conditions comparing to the other models.
\end{abstract}




\section{Keywords}

Solar Radiation, Turbidity Parameters, Angström Coefficient, Aerosols Investigation, Radiometric Models

\section{Introduction}

The atmospheric turbidity is responsible of the attenuation of solar radiation reaching a local area of the Earth surface under cloudless sky conditions. Thus, for a given site where implantation of Photovoltaic and thermal energy will be realized, quality and quantity of solar radiation should be estimated and studied [1]. Since good measurement of solar radiation is strongly dependent on Earth atmosphere state, so it is important to quantify the effect of its constituents where solar irradiance is measured.

The atmospheric turbidity is associated with aerosols and due to the relationship that exists between them and attenuation of solar radiation reaching the Earth surface, different turbidity factors based on radiometric methods have been defined to evaluate the atmospheric turbidity. Among them, the Angström turbidity coefficient which is commonly used [2]. It was introduced by Angström [3] [4] [5] through the following Equation:

$$
\tau_{a}(\lambda)=\beta \lambda^{-\alpha}
$$

where $\lambda^{-\alpha}$ is the aerosol optical thickness at wavelength $\lambda(\mu \mathrm{m}), \beta$ the turbidity coefficient defined at $1 \mu \mathrm{m}$ that quantify the aerosols content and $\alpha$ the wavelength exponent which is related to the size distribution of particles [2].

The Angström coefficient $\beta$ has typical values that vary between 0 and 0.5 . [5] [6] Its zero value refers to a clean atmosphere. Several models may be used to estimate $\beta$ from broadband measurements of solar irradiance and meteorological data when spectral measurements are not available.

In the present paper, we will investigate the Angström turbidity coefficient of a semi-arid region in Algeria with the widely used broadband models. We will analyse the performance of each model and its sensitivity to the atmosphere components using data recorded at the Applied Research Unit for Renewable Energies (URAER, Ghardaï) in the south of Algeria from 2005 to 2008 and those obtained from space measurements during the same period.

\section{Turbidity Models}

Four radiometric models are used to compute the Angström turbidity coefficient. They have been developed by Dogniaux [7], Louche [8], Pinazo [9] and Gueymard [10]. The four models estimate the turbidity coefficient from broadband solar radiation. Each model uses common and different parameters as input. The availability of local measurements of these parameters conditions which model can be applied. We present in this section a brief description of the four radiometric models used to compute the Angström turbidity coefficient $\beta$. 


\subsection{Dogniaux's Model}

The Angström turbidity coefficient $\beta_{\text {Dog }}$ according to Dogniaux is obtained from the empirical formula given by the following equation:

$$
\beta_{\text {Dog }}=\frac{T_{l}-\left[\frac{h+85}{39.5 \exp \left(-w_{p}\right)+47.4}+0.1\right]}{16+0.22 w_{p}}
$$

where $T_{l}$ is the Linke turbidity factor, $h$ the Sun elevation angle in degrees and $w_{p}$ the precipitation amount in centimeter. $w_{p}$ is calculated using the following Equation (32):

$$
w_{p}=0.493 \frac{\phi}{T} \exp \left(26.23-\frac{5416}{T}\right)
$$

where $T$ is the temperature in Kelvin and $\phi$ the relative humidity in fractions of one.

The expression used to evaluate the Linke turbidity factor $T_{l}$ [8] [11] [12] [13] [14] [15] is:

$$
T_{l}=T_{l k} \frac{\frac{1}{\delta_{R a}\left(m_{a}\right)}}{\frac{1}{\delta_{R k}\left(m_{a}\right)}}
$$

where $T_{l k}, \delta_{R k}\left(m_{a}\right)$ and $\delta_{R a}\left(m_{a}\right)$ are respectively the Linke factor according to Kasten, the Rayleigh integral optical thickness and the integral optical thickness. The Linke factor $T_{l k}$ is related to the normal incidence solar irradiance expressed by the Equation:

$$
T_{l k}=(0.9+9.4 \sin (h)) *\left(2 \ln \left(I_{0}\left(\frac{R_{0}}{R}\right)-\ln \left(I_{n}\right)\right)\right)
$$

where $I_{n}, I_{0}, h, R$ and $R_{0}$ are respectively the direct normal solar irradiance in $\mathrm{W} / \mathrm{m}^{2}$, the solar constant, the Sun's elevation angle in degrees and the instantaneous and the mean Sun-Earth distances.

$\delta_{R k}\left(m_{a}\right)$ and $\delta_{R a}\left(m_{a}\right)$ are given by the following Equations:

$$
\begin{gathered}
\frac{1}{\delta_{R a}}\left(m_{a}\right)=6.6296+1.7513 m_{a}-0.1202 m_{a}^{2}+0.0065 m_{a}^{3}-0.00013 m_{a}^{4} \\
\frac{1}{\delta_{R k}}\left(m_{a}\right)=9.4+0.9 m_{a}
\end{gathered}
$$

$m_{a}$ is the air mass given by [16]:

$$
m_{a}=m_{r}\left(\frac{P}{101325}\right)\left[\sin (h)+0.15(3.885+h)^{-1.253}\right]^{-1}
$$

where $P$ is the local pressure in Pascal given by [9]:

$$
P=101325 \exp (-0.0001184 z)
$$


$z$ is the altitude of the location in meter.

\subsection{Louche's Model}

Based on Iqbal C model [8] [17] determine the Angström turbidity coefficient $\beta$ using the solar irradiance data and the aerosol transmittance $\tau_{a}$.

The aerosol transmittance according to Iqbal and Mächler [17] [18] [19] is given by:

$$
\tau_{a}=(0.12445 \alpha-0.0162)+(1.003-0.125 \alpha) \exp \left[-\beta m_{a}(1.089 \alpha+0.5123)\right]
$$

Louche's et al. [20] expressed the aerosol transmittance for cloudless sky as:

$$
\tau_{a}=\frac{1}{0.9751 I_{n} E_{0} \tau_{g} \tau_{0} \tau_{r} \tau_{w}}
$$

The direct solar irradiance at normal incidence $I_{n}$ in $\mathrm{W} / \mathrm{m}^{2}$, is directly measured with a pyrheliometer.

The Earth eccentricity correction factor $E_{0}$ is given by:

$$
E_{0}=\left(\frac{R}{R_{0}}\right)^{2}
$$

where $R$ and $R_{0}$ are the same as defined in Equation (5).

The parameter $\tau_{g}$ represents the mixing gases absorption transmittance given by:

$$
\tau_{g}=\exp \left(-0.0127 m_{a}^{0.26}\right)
$$

The parameter $\tau_{0}$ is the ozone absorption transmittance given by:

$$
\begin{aligned}
\tau_{0}= & 1-\left[0.1611 U_{3}\left(1+139.48 U_{3}\right)^{-0.3035}\right. \\
& \left.-0.002715 U_{3}\left(1+0.044 U_{3}+0.0003 U_{3}^{2}\right)^{-1}\right]
\end{aligned}
$$

where $U_{3}=m_{r} l$. ( $l$ is the thickness of the total vertical ozone layer in $\mathrm{cm}$ ).

The parameter $\tau_{r}$ is the Rayleigh scattering transmittance given by:

$$
\tau_{r}=\exp \left(-0.0903 m_{a}^{0.84}\left(1+m_{a}-m_{a}^{1.01}\right)\right)
$$

The parameter $\tau_{w}$ is the water vapor transmittance expressed as follow:

$$
\tau_{w}=1-2.4959 U_{1}\left(\left(1+0.79034 U_{1}\right)^{0.6828}+6.385 U_{1}\right)^{-1}
$$

where $U_{1}=w_{p} m_{r}$ and $w_{p}$ is calculated by Equation (3).

The expression of the Angström coefficient denoted $\beta_{\text {Louch }}$ in the following, is obtained from a combination of Equations (10) and (11):

$$
\beta_{\text {Louch }}=\frac{1}{m_{a} D_{3}} \log \left(\frac{D_{2}}{\tau_{a}-D_{1}}\right)
$$

where $D_{1}=0.12445 \alpha-0.0162, D_{2}=1.003-0.125 \alpha$ and $D_{3}=1.089 \alpha+0.5123$. 


\subsection{Pinazo's Model}

The approach developed by Pinazo et al. [9] is also based on Iqbal C model and on a coefficient $K$ which is defined as the ratio between the direct beam solar irradiance on a horizontal surface and the global solar irradiance received by the same surface. The aerosol transmittance according to Pinazo et al. is expressed as:

$$
\tau_{a}=\frac{(1-A) C}{1-A C}
$$

with $A=\left(1-w_{0}\right)\left(1-m_{a}+m_{a}^{1.06}\right)$ and $C=C_{1}-C_{2}$.

The parameter $w_{0}$ is the single scattering albedo or the ratio between the scattering and the extinction (scattering plus absorption) coefficients of aerosols that are high above the ground.

$C_{1}$ and $C_{2}$ are given by:

$$
\begin{gathered}
C_{1}=\left(\left[\frac{1+\left(F_{c} B-1\right) K-\rho_{g}\left(1.0685-F_{c}\right)}{2 \rho_{g}\left(1-F_{c}\right)}\right]^{2}+B K\left[\frac{0.5\left(1-\tau_{r}\right)+F_{c}}{\left(1-F_{c}\right) \rho_{g}}\right]\right)^{0.5} \\
C_{2}=\frac{1+\left(F_{c} B-1\right) K-\rho_{g}\left(1.0685-F_{c}\right)}{2 \rho_{g}\left(1-F_{c}\right)}
\end{gathered}
$$

where

$$
B=\frac{0.79}{0.9751 \tau_{r}\left(1-m_{a}+m_{a}^{1.02}\right)}
$$

$F_{c}$ is the forward scattering parameter defining the radiation fraction scattered in the forward half-space and $\rho_{g}$ is the albedo of the ground.

The Angström coefficient according to this model will be denoted $\beta_{\text {Pinz }}$ and will be calculated using a combination of Equations (10) and (18).

\subsection{Gueymard's Model}

Gueymard and Vignola [10] proposed a method for estimating the Angström coefficient using the relation between the global (or diffuse) and the direct irradiance based on the spectral code SMARTS2 [10] [21]. The Angström coefficient denoted $\beta_{\text {Gyem }}$ is obtained from the following Equation (2):

$$
\beta_{\text {Gyem }}=0.5\left(\frac{\left[a_{1}^{2}-4\left(a_{2}-a_{3} K_{a b}\right)\left(a_{0}-K_{a b}\right)\right]^{0.5}-a_{1}}{a_{2}-a_{3} K_{a b}}\right)
$$

where $K_{a b}$ is the ratio between the diffuse irradiance and the direct beam normal irradiance. It corresponds to a standard value for zero altitude and the total amount of ozone equal to $0.3434 \mathrm{~atm}-\mathrm{cm}$. The coefficients $a_{i}$ are function of the zenith Sun angle, the pressure, the perceptible water and the ozone amount. These coefficients and the way they are calculated are detailed in [10].

\section{Site Location and Solar Radiation Data}

The data used in the present study is collected at the Applied Research Unit for 
Renewable Energies (URAER, Algeria). The three components of solar irradiance (Direct, Diffuse and Global) in addition to meteorological parameters (Temperature and humidity) are measured by a frequency of 5 minutes (see the details in [1]).

Data recorded between 2005 and 2008 are used to calculate the Angström coefficient using the above radiometric models. The data are selected taking only those corresponding to cloudless conditions clear skies. We have considered the following requirements applied by many authors to identify the cloudless conditions [2] [17] [22]-[28]:

1) Direct normal irradiance greater than $200 \mathrm{~W} / \mathrm{m}^{2}$

2) Ratio between diffuse and global irradiance less than $1 / 3$

3) Perez's clearness index greater than 4.5

4) Data corresponding to solar elevations higher than 5 degrees to avoid cosine response problems of radiometric sensors

For the common and the different parameters used as inputs by the four models and how to evaluate them in case where local measurements are not available will be detailed in the following subsections.

\subsection{Thickness of the Total Vertical Ozone Layer}

We take daily mean values of the thickness of the total vertical ozone layer 1 from MODIS satellite data Ichoku 2004 [29] since we have no local measurements for this parameter. Figure 1 plots the temporal variation of the daily ozone layer thickness values for the period 2005-2008 (upper side) and its frequency distribution (bottom side). Annual mean values of the ozone layer thickness are $0.297 \mathrm{~cm}, 0.296 \mathrm{~cm}, 0.299 \mathrm{~cm}$ and $0.296 \mathrm{~cm}$ for 2005, 2006, 2007 and 2008 respectively. Similar 1 values are also obtained with data of the OMI instrument Torres 2002 [30]. We notice a higher value of this parameter and a more pronounced max in 2007. The maximum occurrence value of ozone layer thickness is around $0.285 \mathrm{~cm}$ according to Figure 1.

\subsection{Total Precipitable Water}

The total precipitable water is defined as the integrated water vapor in a vertical column extending from the surface to the top of the atmosphere. This parameter is important and its influence in calculation should be studied especially that in most cases we have absence of atmospheric sounding or solar spectral measurements [2]. We have used four algorithms in the present study to estimate the precipitable water:

1) Wright's formula: A linear relationship relates the logarithm of the precipitable water $w$ to the dew point temperature $T_{d}$ [17]:

$$
\ln w=a+b T_{d}
$$

Parameters $a$ and $b$ are not universal and have both site and time dependency. The mostly used values of these parameters by several authors are those obtained by [31] for Albany NY: $a=-0.0756$ and $b=0.0693$ [2]. These values are 

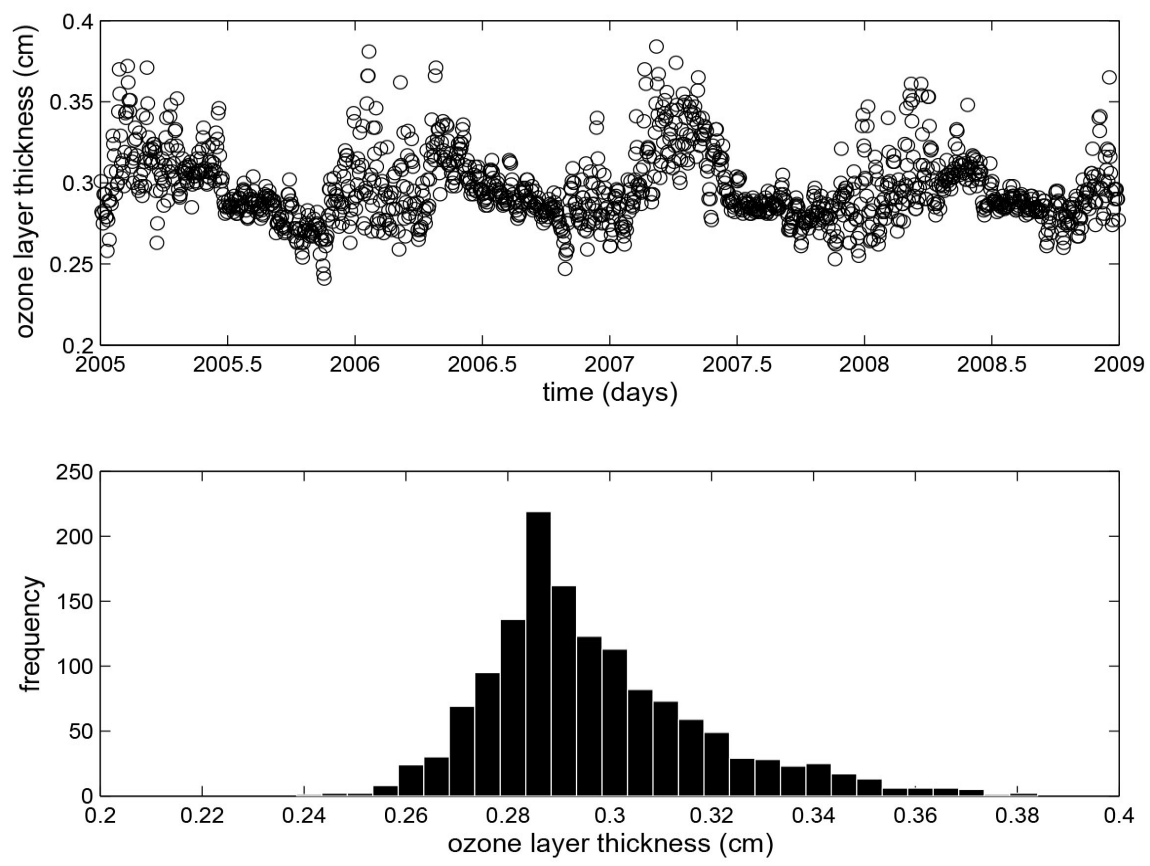

Figure 1. Upper-side: Temporal variations of the ozone layer thickness for the period 2005-2008. Bottom-side: Frequency distribution of the ozone layer thickness values from 2005 to 2008 .

suitable for estimating instantaneous precipitable water under cloudless skies [31]. Two sources of error affect calculation of $T_{d}$. They are associated to local parameters $a$ and $b$ and to the calculation method. The parameter $T_{d}$ is calculated by:

$$
p_{s}\left(T_{d}\right)=p_{v}(T)=\Phi p_{s}(T)
$$

where $T$ is the temperature, $\Phi$ the relative humidity and $p_{s}$ the saturation pressure of water vapor calculated with several algorithms among them the commonly used Magnus and Leckner algorithms. The $p_{s}$, in mbar, is expressed for each algorithm by Equations (25) and (26):

$$
\begin{gathered}
p_{s}^{M}=6.107 \exp \left(\frac{17.38 T}{239+T}\right) \\
p_{s}^{L}=0.01 \exp \left(26.23-\frac{5416}{273.15+T}\right)
\end{gathered}
$$

where $T$ is in degrees and $\Phi$ in fraction of one. $M$ and $L$ letters associted to $p_{s}$ variable stand for Magnus and Leckner respectively.

Equations (24), (25) and (26) lead to calculate $T_{d}$ with the desired algorithm using the following equations (Equation (27) and (28))

$$
\begin{gathered}
T_{d}^{M}=\frac{239 f(T, \Phi)}{17.38-f(T, \Phi)} \text { where } f(T, \Phi)=\ln \Phi+\frac{17.38 T}{239+T} \\
T_{d}^{L}=\frac{5416}{5416 /(273.15+T)-\ln \Phi}-273.15
\end{gathered}
$$


We have then two precipitable water values $w_{M}^{w}$ and $w_{L}^{w}$ according to Equations (27) and (28) and Wright's formula 23.

2) Leckner's formula: This alternative method is often used to calculate the amount of precipitable water $w_{L}$ [32]. It is obtained with the folling Equation:

$$
w_{L}=49.3 \frac{\Phi p_{s}^{L}}{T}
$$

3) Gueymard's formula: Gueymard introduced a new formula in 1994 [33] to estimate the precipitable water $w_{G}$. It is expressed as follow:

$$
w_{G}=21.67 H_{v} \frac{\Phi p_{s}^{G}}{T}
$$

with $p_{s}^{G}$ and $H_{v}$ are given by Equation (31) and (32):

$$
\begin{gathered}
\ln p_{s}^{G}=22.33-\frac{4914}{T}-\frac{10922000}{T^{2}}-0.003902 T \\
H_{v}=\exp \left(13.6897 \theta-14.9188 \theta^{3}\right)+1.5265 \theta+0.4976, \theta=T / 273
\end{gathered}
$$

Annual mean values of the precipitable water $w_{p}$ according to the previous four methods are plotted in Figure 2. We notice that $w_{p}$ obtained with the 4 years of data have the same temporal trend. All methods show a minimum in May and a maximum between July and October. Maximum values are obtained with Leckner model $\left(w_{L}\right)$ and the minimum with Magnus using Wright's formula $\left(w_{M}^{w}\right)$. Gueymards method $\left(w_{G}\right)$ and Leckner using Wright's formula $\left(w_{L}^{w}\right)$ give approximately the same mean values (see Table 1 ). We will use precipitable water values of each method to estimate the Angström turbidity coefficient with the four broadband models. We notice however, that this parameter obtained from the four methods has not a significant effect on turbidity values for a given broadband model. The difference is about $0.1 \%$.

\subsection{The Wavelength Exponent}

The wavelength exponent $\alpha$ in Equation (1) is related to size distribution of particles. Low values of $\alpha$ correspond to large particles and vice versa. $\alpha=1.3 \pm 0.5$ is suggested by many authors for most natural atmospheres [16]. In our case, we will use MODIS satellite data to obtain the values of this parameter since we did not dispose of photometric ground measurements. The variation of its monthly mean values over Ghardaïa city is shown in the upper side of Figure 3. Its yearly mean value is plotted in the lower side of Figure 3 where a slightly increase is observed. The annual mean values are $1.0 \pm 0.3,1.0 \pm 0.3$, $1.0 \pm 0.3,1.1 \pm 0.3$ for $2005,2006,2007$ and 2008 respectively. The mean value of $\alpha$ over the four years is $1.0 \pm 0.3$ and it is in agreement with values suggested by many authors.

\subsection{The Ground Albedo}

We also used MODIS data to estimate the ground albedo $\rho_{g}$ at Ghardaïa city. Variations of its monthly value are shown in the upper side of Figure 4 ant its 


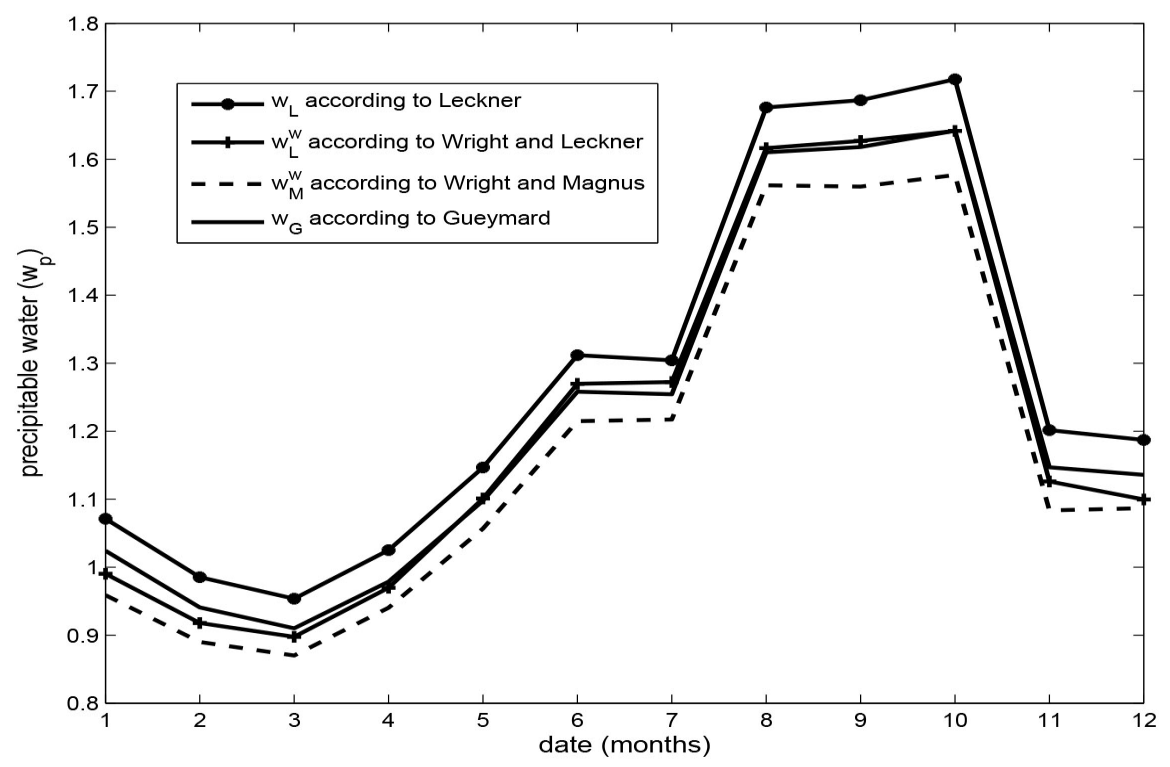

Figure 2. Precipitable water according to the four methods.

Table 1. Monthly average values of the total precipitable water using four methods.

\begin{tabular}{ccccc}
\hline & $w_{L}$ & $w_{M}^{w}$ & $w_{L}^{w}$ & $w_{G}$ \\
\hline January & $1.071 \pm 0.038$ & $0.959 \pm 0.034$ & $0.990 \pm 0.048$ & $1.024 \pm 0.037$ \\
February & $0.985 \pm 0.020$ & $0.890 \pm 0.019$ & $0.918 \pm 0.025$ & $0.941 \pm 0.019$ \\
March & $0.954 \pm 0.050$ & $0.870 \pm 0.043$ & $0.898 \pm 0.061$ & $0.910 \pm 0.047$ \\
April & $1.025 \pm 0.064$ & $0.940 \pm 0.059$ & $0.970 \pm 0.045$ & $0.979 \pm 0.061$ \\
May & $1.147 \pm 0.050$ & $1.057 \pm 0.045$ & $1.101 \pm 0.046$ & $1.098 \pm 0.048$ \\
June & $1.312 \pm 0.099$ & $1.215 \pm 0.091$ & $1.270 \pm 0.102$ & $1.258 \pm 0.096$ \\
July & $1.304 \pm 0.019$ & $1.217 \pm 0.019$ & $1.272 \pm 0.021$ & $1.254 \pm 0.019$ \\
August & $1.676 \pm 0.119$ & $1.562 \pm 0.053$ & $1.616 \pm 0.060$ & $1.610 \pm 0.057$ \\
September & $1.687 \pm 0.111$ & $1.560 \pm 0.104$ & $1.627 \pm 0.116$ & $1.618 \pm 0.107$ \\
October & $1.718 \pm 0.114$ & $1.577 \pm 0.145$ & $1.642 \pm 0.147$ & $1.642 \pm 0.137$ \\
November & $1.202 \pm 0.038$ & $1.084 \pm 0.036$ & $1.126 \pm 0.048$ & $1.147 \pm 0.035$ \\
December & $1.187 \pm 0.608$ & $1.087 \pm 0.617$ & $1.100 \pm 0.622$ & $1.136 \pm 0.587$ \\
Mean & $1.272 \pm 0.113$ & $1.168 \pm 0.110$ & $1.211 \pm 0.117$ & $1.218 \pm 0.108$ \\
\hline
\end{tabular}

annual mean values plotted in the lower side. The annual mean values are $0.17 \pm 0.06,0.18 \pm 0.05,0.17 \pm 0.05,0.18 \pm 0.05$ for 2005, 2006, 2007 and 2008 respectively. The $\rho_{g}$ mean value over the four years is $0.17 \pm 0.05$. We note also a slightly increase of $\rho_{g}$ between 2005 and 2008 with a litte drop in 2007.

\subsection{Single Scattering Albedo and Forward Scattering}

The value of 0.8 for the single scattering albedo $w_{0}$ is usually chosen for rural-urban sites as advised by Gueymard [34] [35] while a value of 0.84 is 

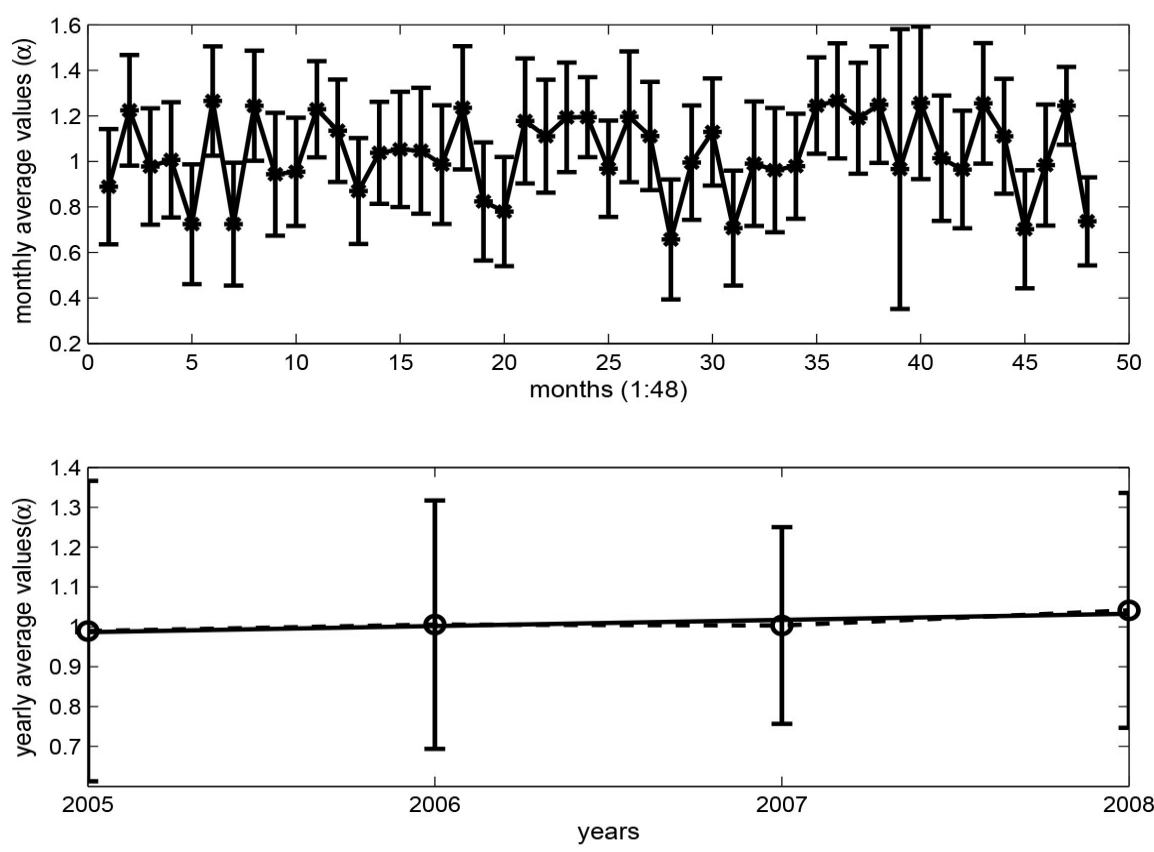

Figure 3. Upper-side: Variations of monthly mean values of the wavelength exponent for the period 2005-2008. Lower-side: Variations of yearly mean values of wavelength exponent from 2005 to 2008.
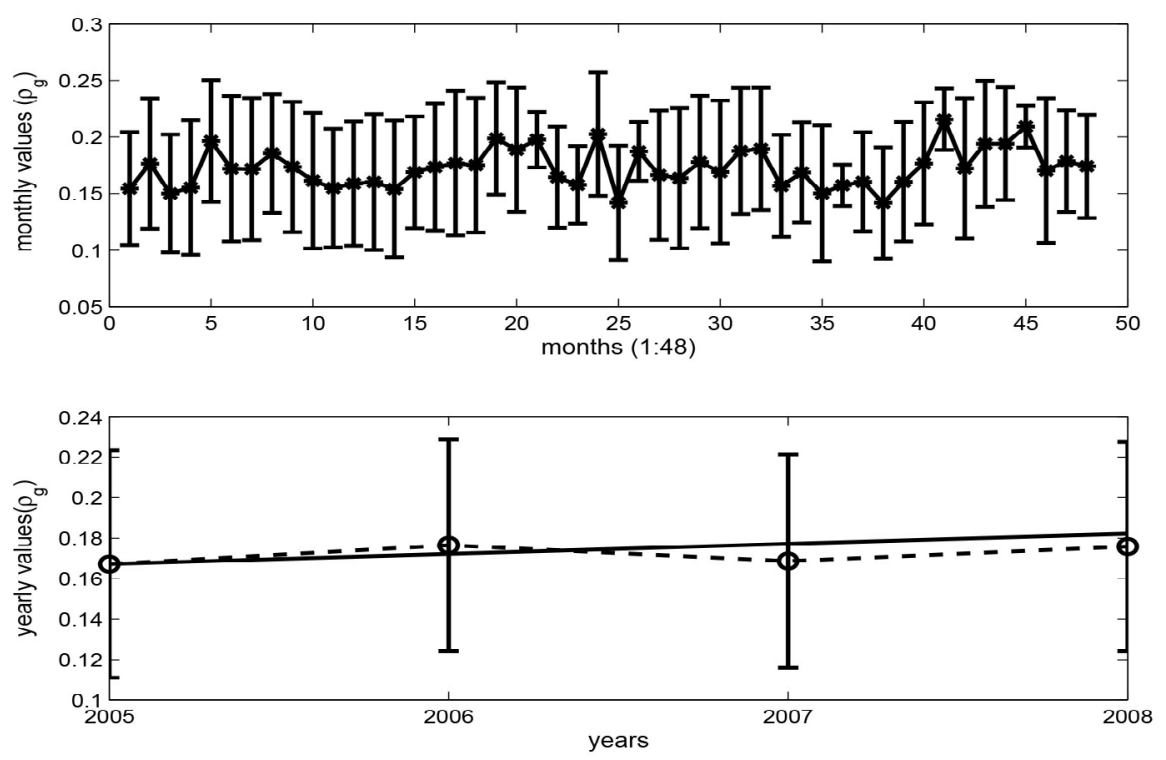

Figure 4. Upper-side: Variations of monthly mean values of the ground albedo for the period 2005-2008. Lower-side: Variations of yearly mean values of ground albedo from 2005 to 2008 .

suggested by [17] for the forward scattering $F_{c}$. We preferred here to use modeling techniques to find these parameters and their temporal variations rather than a constant value. In a recent study, [36] assessed the intrinsic performance of 18 broadband radiative models using high-quality data sets from five sites in widely different climates. All these models are able to predict direct, diffuse and 
global irradiance under clear skies from atmospheric data. Intrinsic performances of these models were evaluated by comparison between their predictions and high frequency measurements (1-minute time step in four sites, 3-minute in one site). From the 18 models is the Iqbal C [17] model that requires a relatively large number of atmospheric inputs and showed consistently high scores of statistical indicators. This model will be considered in our present study to estimate the required parameters since it offers a better accuracy than the others more conventional models [36]. In addition, the model inputs are those that we need, namely the Angstrom coefficient $\beta$, the average surface albedo $\rho_{g}$, the wavelength Angstrom exponent $\alpha$, the forward scatterance $F_{c}$ and the aerosol single scattering albedo $w_{0}$. Only the last two parameters and the Angstrom coefficient $\beta$ will be considered since the others are obtained from MODIS data (see Sections 3.3 and 3.4). Before proceeding the estimation of the parameters, we recall hereafter the main equations of this model described in detail in [17].

The direct normal irradiance $I_{n}\left(\mathrm{~W} / \mathrm{m}^{2}\right)$ is given by:

$$
I_{n}=0.9751 I_{s c} E_{0} \tau_{0} \tau_{g} \tau_{w} \tau_{r} \tau_{a}(\alpha, \beta)
$$

where $\tau_{0}, \tau_{g}, \tau_{w}, \tau_{r}$ and $\tau_{a}(\alpha, \beta)$ are respectively the ozone, gas, water, Rayleigh and aerosol scattering transmittances. $I_{s c}$ and $E_{0}$ are respectively the solar constant and the eccentricity correction factor.

The aerosol scattering transmittance, which depends on the Angstrom coefficient $\beta$ and wavelength Angstrom exponent $\alpha$, is given by Equation (10).

The global solar irradiance $\left(I_{t}\right)$ measured with our instruments is the contribution of 2 solar irradiance components given by:

$$
I_{t}=I_{n h}+I_{d}
$$

where $\left(I_{n h}\right)$ is the normal solar irradiance on an horizontal surface and $\left(I_{d}\right)$ the horizontal diffuse solar irradiance. The normal solar irradiance $I_{n h}\left(\mathrm{~W} / \mathrm{m}^{2}\right)$ is given by:

$$
I_{n h}=I_{n} \sin (h)
$$

where $h$ is the elevation angle of Sun in degrees.

The horizontal diffuse solar irradiance $I_{d}\left(\mathrm{~W} / \mathrm{m}^{2}\right)$ is a combination of three individual components, which are the Rayleigh component, $I_{d r}\left(\mathrm{~W} / \mathrm{m}^{2}\right)$, the aerosols scattering component, $I_{d a}\left(\mathrm{~W} / \mathrm{m}^{2}\right)$ after the first pass through the atmosphere, and the multiple reflection processes between the ground and sky component, $I_{d m}\left(\mathrm{~W} / \mathrm{m}^{2}\right)$ :

$$
I_{d}=I_{d r}+I_{d a}+I_{d m}
$$

The $I_{d r}$ component which depends on aerosol single scattering albedo $w_{0}$, is given by:

$$
I_{d r}\left(w_{0}\right)=0.395 \tau_{0} \tau_{g} \tau_{w}\left(1-\tau_{r}\right) \frac{I_{s c} E_{0} \sin (h)}{1-m_{a}+m_{a}^{1.02}} \tau_{a a}
$$

where $\tau_{a a}=1-\left(1-w_{0}\right)\left(1-m_{a}+m_{a}^{1.06}\right)\left(1-\tau_{a}\right)$ is the direct radiation 
transmittance due to aerosol absorptance.

The $I_{d a}$ component is related to the forward scatterance $F_{c}$ :

$$
I_{d a}\left(F_{c}\right)=0.79 \tau_{0} \tau_{g} \tau_{w} \tau_{a a} F_{c}\left(1-\tau_{a s}\right) \frac{I_{s c} E_{0} \sin (h)}{1-m_{a}+m_{a}^{1.02}}
$$

The $I_{d m}$ component related to the ground albedo $\rho_{g}$, is given by:

$$
I_{d m}\left(\rho_{g}\right)=\left(I_{n h}+I_{d r}+I_{d a}\right) \frac{\rho_{g} \rho_{a}}{1-\rho_{g} \rho_{a}}
$$

where $\rho_{a}$ is the albedo of the cloudless sky, which can be computed with:

$$
\rho_{a}=0.0685+\left(1-F_{c}\right)\left(1-\frac{\tau_{a}}{\tau_{a a}}\right)
$$

The $\left(1-F_{c}\right)$ term corresponds to the back-scatterance. The second term on the right hand side of Equation (40) represents the albedo of cloudless skies due to the presence of aerosols, whereas the first term is the albedo of clean air.

The global solar irradiance $\left(I_{t}\right)$ on a horizontal surface is then expressed by:

$$
I_{t}=I_{n h}+I_{d}=\left(I_{n} \sin (h)+I_{d r}+I_{d a}\right) \frac{1}{1-\rho_{g} \rho_{a}}
$$

We will fit the recorded global solar irradiance $\left(I_{t r}\right)$ of clear days with Iqbal C model given by Equation (41). The method consists to solve a nonlinear fitting problem in the least-squares sense i.e. we look for the $x$-vector coefficients $\left(\beta, w_{0}, F_{c}\right)$ that minimize the following residual function:

$$
\left\|I_{q b a l}(x)-I_{t r}\right\|^{2}=\sum_{i}\left(I_{q b a l}\left(x_{i}\right)-I_{t r}\right)^{2}
$$

where $I_{q b a l}(x)=I_{t}\left(\beta, w_{0}, F_{c}\right)$ is the Iqbal $\mathrm{C}$ model. Figure 5 plots a recorded global solar irradiance component of a clear day superposed to its fit by Iqbal C model.

We will apply this process to all global solar irradiance of clear days of the recorded data. The clear days are determined using the novel method developed by [37]. Each fit will give us a value of the aerosol single scattering albedo $w_{0}$ and a value of the forward scatterance $F_{c}$. The monthly and the yearly mean values of these two parameters are shown in Figure 6 and Figure 7 respectively. The annual mean values vary between $0.80 \pm 0.04$ and $0.81 \pm 0.04$ for the aerosol single scattering albedo $w_{0}$ and between $0.82 \pm 0.04$ and $0.85 \pm 0.04$ for the forward scatterance $F_{c}$. We note that the two parameters vary in opposite of phase with each other with particular values during 2007.

\section{Results and Discussion}

All useful parameters described in the previous section are used to calculate the Angstrom coefficient obtained with the four turbidity models. The coefficients $\beta_{\text {Dog }}, \beta_{\text {Louch }}, \beta_{\text {Pinz }}$ and $\beta_{\text {Gyem }}$ are respectively calculated with models of Dogniaux, Louche, Pinazo and Gueymard. $\beta_{\text {modis }}$ is the Angstrom coefficient 


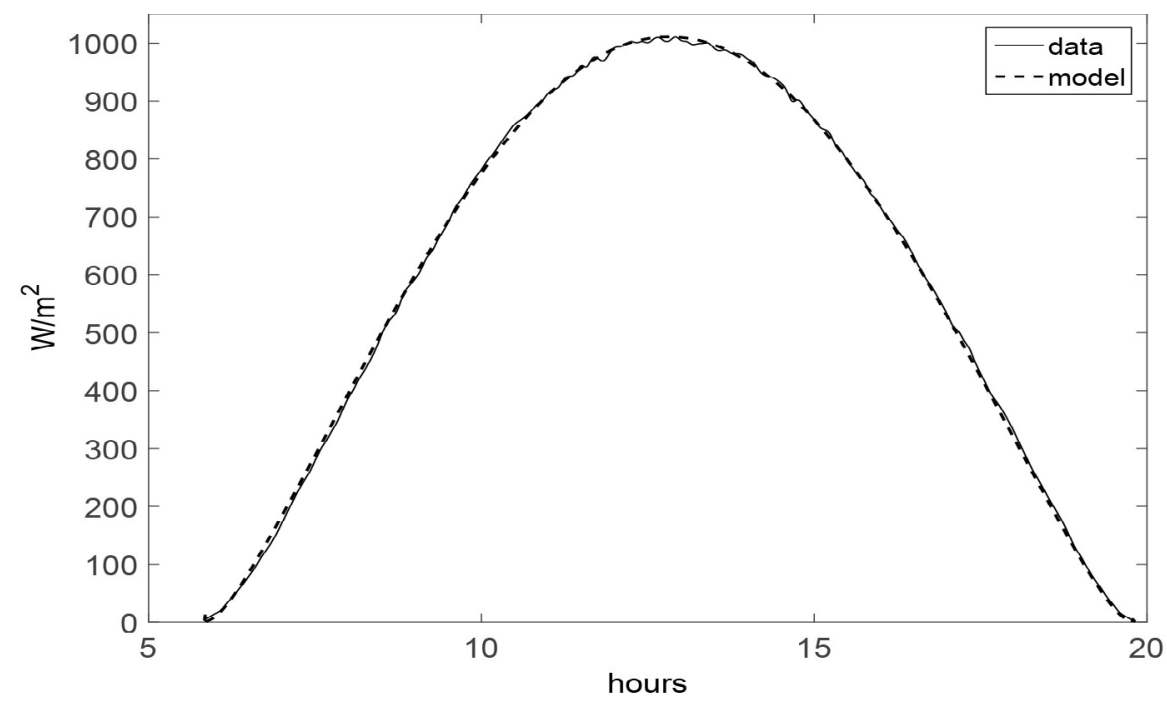

Figure 5. A recorded solar irradiance component of a clear day (full line) superposed to its fit obtained with Iqbal C model (dashed line).
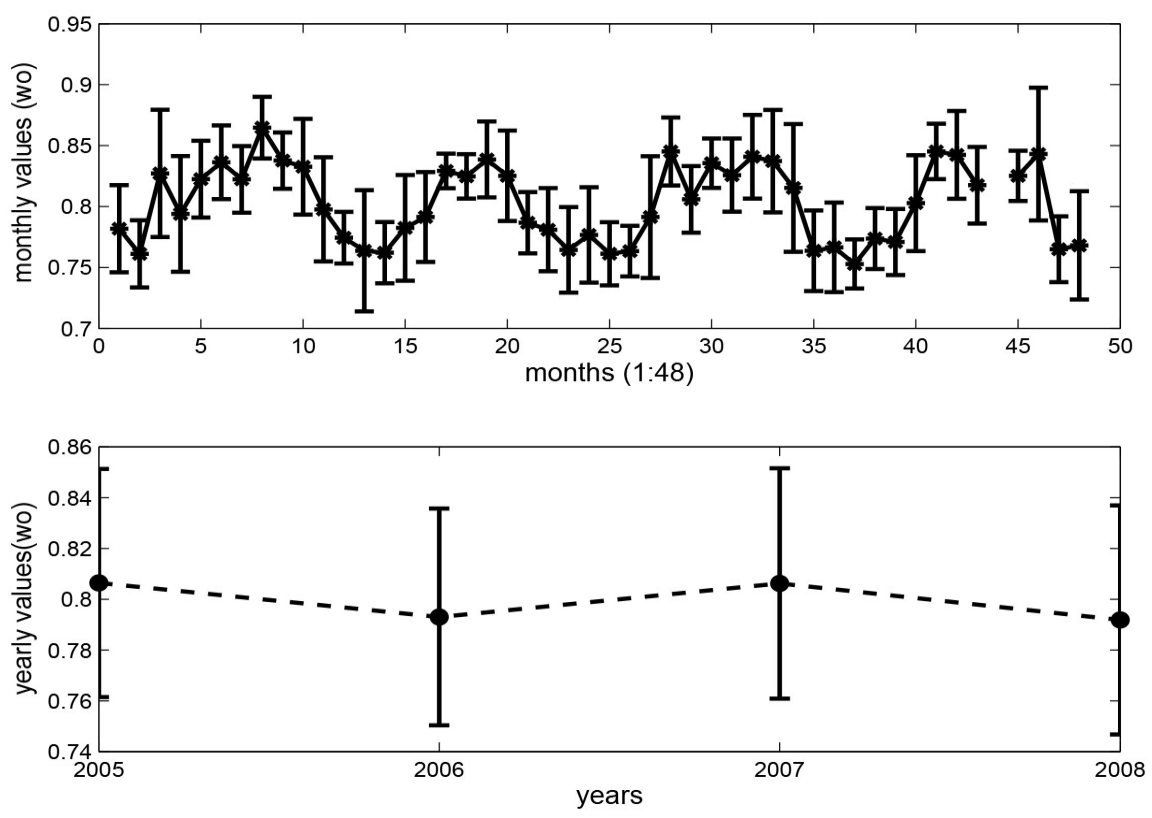

Figure 6. Upper-side: Variations of monthly mean values of the aerosol single scattering albedo w0 for the period 2004-2008. Lower-side: Variations of yearly mean values of the aerosol single scattering albedo w0 from 2005 to 2008.

obtained from space data recorded with the MODIS instrument aboard the Terra satellite (NASA). All these Angström turbidity coefficients are shown in Figure 8. Temporal variations of the monthly values of $\beta$ for the period 2005-2008 are plotted in the upper side of Figure 8. The mean values for each month calculated over the same period are shown in the lower side of this figure. These values are reported in Table 2. We notice from Figure 8 that $\beta_{\text {Gyem }}$ and $\beta_{\text {Pinz }}$ are very close as $\beta_{\text {Dog }}$ and $\beta_{\text {modis }} . \beta_{\text {Louch }}$ are in the average of all models. We observe in addition that differences of $\beta$ values range from 50 up 

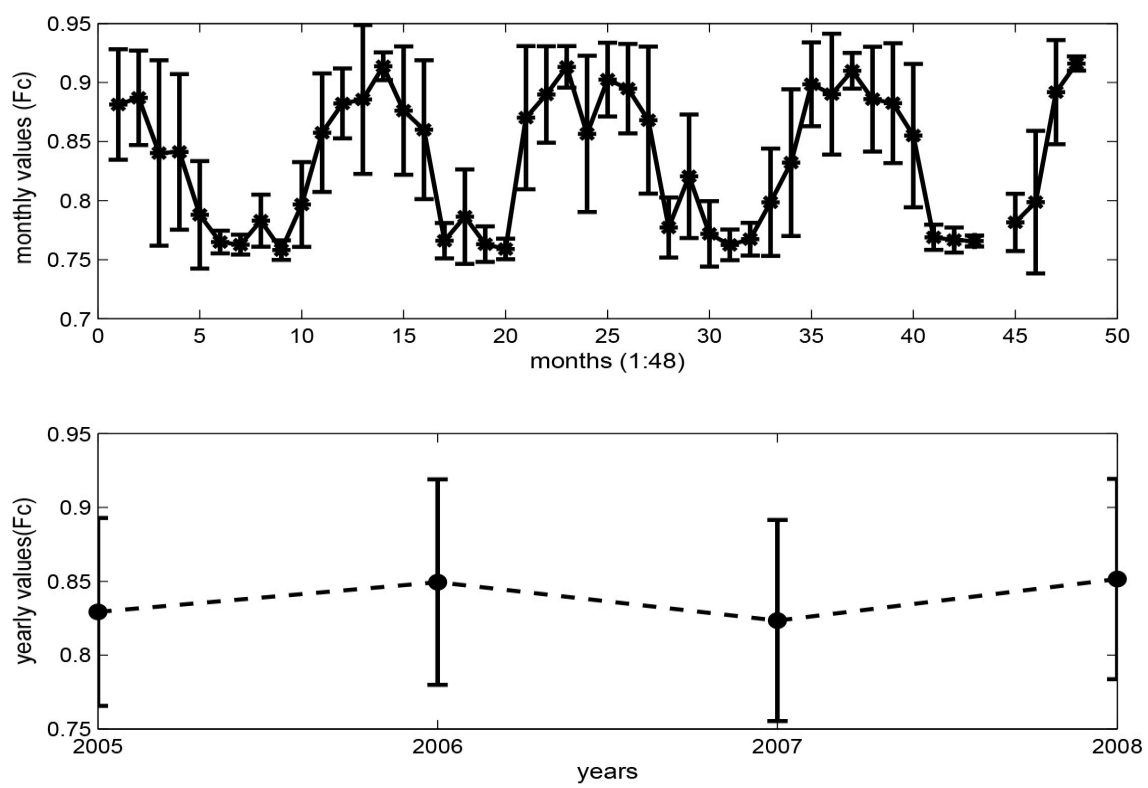

Figure 7. Upper-side: Variations of monthly mean values of the forward scatterance Fc for the period 2004-2008. Lower-side: Variations of yearly mean values of the forward scatterance Fc from 2005 to 2008.
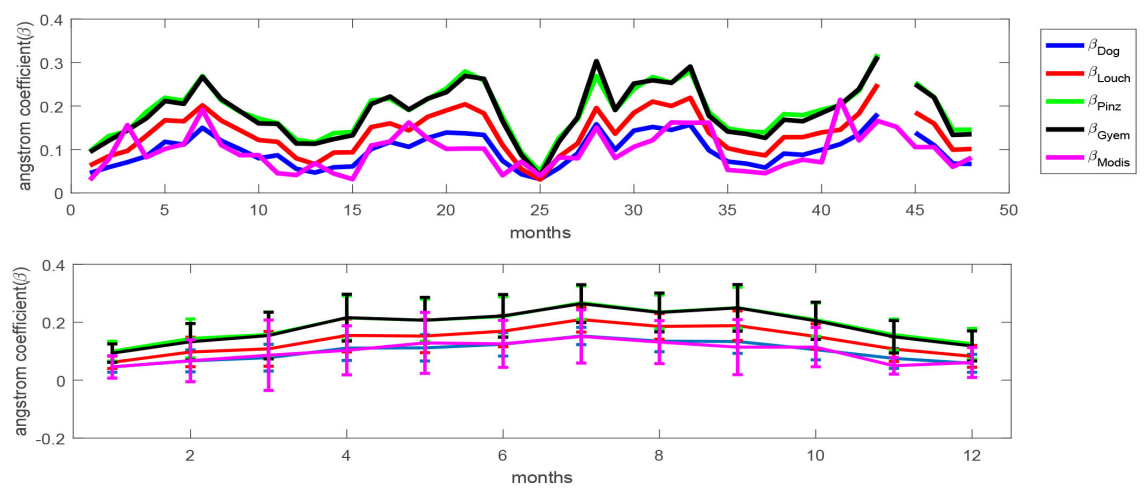

Figure 8. Monthly mean values of the angstrom coefficient $\beta_{\text {Dog }}, \beta_{\text {Louch }}, \beta_{\text {Pinz }}, \beta_{\text {Gyem }}$ and $\beta_{\text {modis }}$ for the period 2005-2008.

to $100 \%$. We also note that Angström coefficient curves have all the same shape during the period 2005-2008 and along the year where maximum and minimum are respectively during summer and winter months. We can explain it by winds of the south sectors (Sirocco) that characterize the region of Ghardaïa. This kind of winds brings particles of dust and sand with them, which increases the Angström coefficient. It is well observed in Figure 6 where $w_{0}$ is higher in summer and consequently contributes to light extinction due to aerosol scattering. The period of winter is characterized by rains (see Figure 2) that wash the atmosphere and diminish turbidity variables.

Annual mean values of $\beta$ obtained from the models and from space are plotted in Figure 9 and given in Table 3. We can notice three points:

1) $\beta_{\text {Pinz }} \simeq \beta_{\text {Gyem }}>\beta_{\text {Louch }}>\beta_{\text {modis }} \simeq \beta_{\text {Dog }}$ 
Table 2. Monthly average values of the Angström turbidity coefficient according to the fifth methods.

\begin{tabular}{cccccc}
\hline & $\beta_{\text {Dog }}$ & $\beta_{\text {Louch }}$ & $\beta_{\text {Pinz }}$ & $\beta_{\text {Gyem }}$ & $\beta_{\text {modis }}$ \\
\hline January & $0.046 \pm 0.018$ & $0.062 \pm 0.021$ & $0.100 \pm 0.034$ & $0.093 \pm 0.032$ & $0.050 \pm 0.045$ \\
February & $0.067 \pm 0.038$ & $0.097 \pm 0.051$ & $0.144 \pm 0.067$ & $0.133 \pm 0.063$ & $0.061 \pm 0.067$ \\
March & $0.076 \pm 0.046$ & $0.108 \pm 0.060$ & $0.158 \pm 0.078$ & $0.154 \pm 0.081$ & $0.077 \pm 0.104$ \\
April & $0.111 \pm 0.043$ & $0.154 \pm 0.057$ & $0.215 \pm 0.076$ & $0.216 \pm 0.081$ & $0.106 \pm 0.090$ \\
May & $0.112 \pm 0.045$ & $0.152 \pm 0.054$ & $0.207 \pm 0.073$ & $0.207 \pm 0.079$ & $0.120 \pm 0.108$ \\
June & $0.124 \pm 0.041$ & $0.160 \pm 0.043$ & $0.219 \pm 0.068$ & $0.222 \pm 0.074$ & $0.123 \pm 0.097$ \\
July & $0.153 \pm 0.030$ & $0.209 \pm 0.044$ & $0.268 \pm 0.057$ & $0.264 \pm 0.065$ & $0.134 \pm 0.099$ \\
August & $0.135 \pm 0.037$ & $0.186 \pm 0.051$ & $0.236 \pm 0.058$ & $0.234 \pm 0.067$ & $0.114 \pm 0.080$ \\
September & $0.133 \pm 0.041$ & $0.188 \pm 0.044$ & $0.250 \pm 0.071$ & $0.250 \pm 0.081$ & $0.110 \pm 0.097$ \\
October & $0.105 \pm 0.035$ & $0.151 \pm 0.043$ & $0.209 \pm 0.057$ & $0.205 \pm 0.064$ & $0.095 \pm 0.095$ \\
November & $0.075 \pm 0.035$ & $0.107 \pm 0.043$ & $0.157 \pm 0.054$ & $0.150 \pm 0.056$ & $0.044 \pm 0.031$ \\
December & $0.058 \pm 0.031$ & $0.082 \pm 0.038$ & $0.126 \pm 0.053$ & $0.118 \pm 0.052$ & $0.059 \pm 0.056$ \\
\hline
\end{tabular}

Table 3. Annual mean values of the Angström turbidity coefficient obtained with the four methods and from space.

\begin{tabular}{cccccc}
\hline & $\beta_{\text {Dog }}$ & $\beta_{\text {Louch }}$ & $\beta_{\text {Pinz }}$ & $\beta_{\text {Gyem }}$ & $\beta_{\text {modis }}$ \\
\hline 2005 & $0.090 \pm 0.035$ & $0.128 \pm 0.045$ & $0.176 \pm 0.058$ & $0.171 \pm 0.060$ & $0.093 \pm 0.081$ \\
2006 & $0.095 \pm 0.037$ & $0.135 \pm 0.048$ & $0.190 \pm 0.065$ & $0.185 \pm 0.070$ & $0.090 \pm 0.063$ \\
2007 & $0.106 \pm 0.040$ & $0.142 \pm 0.049$ & $0.193 \pm 0.065$ & $0.195 \pm 0.071$ & $0.104 \pm 0.076$ \\
2008 & $0.104 \pm 0.034$ & $0.146 \pm 0.046$ & $0.201 \pm 0.060$ & $0.194 \pm 0.064$ & $0.106 \pm 0.083$ \\
\hline
\end{tabular}

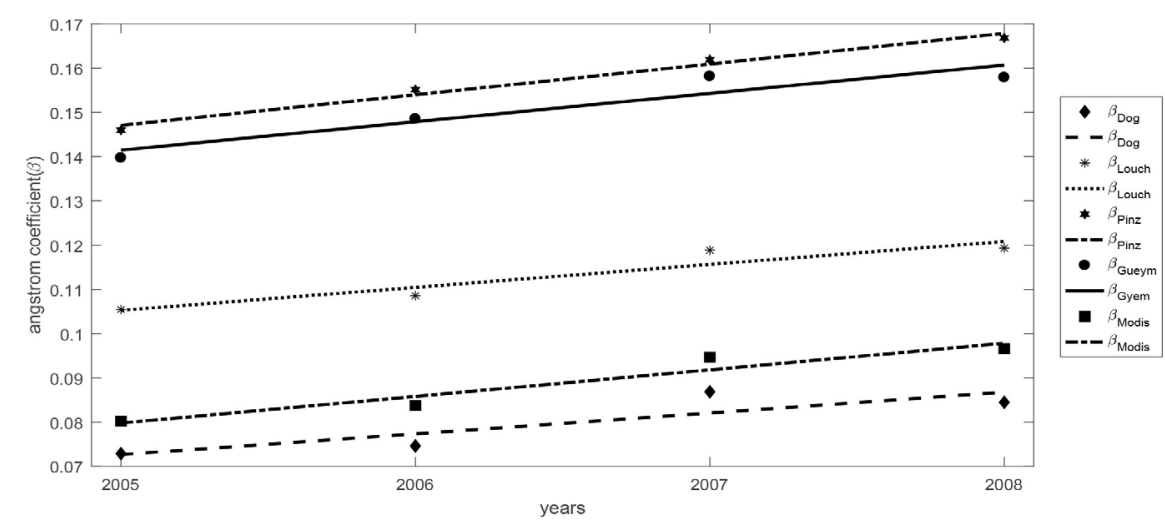

Figure 9. Annual mean values of the angstrom coefficient $\beta_{\text {Dog }}, \beta_{\text {Louch }}, \beta_{\text {Pinz }}, \beta_{\text {Gyem }}$ and $\beta_{\text {modis }}$ for the period 2005-2008.

2) $\beta_{\text {Pinz }}, \beta_{\text {Gyem }}, \beta_{\text {Louch }}, \beta_{\text {modis }}$ and $\beta_{\text {Dog }}$ increases from 2005 to 2008

3) $\beta_{\text {Gyem }}, \beta_{\text {modis }}, \beta_{\text {Dog }}$ and $\beta_{\text {Pinz }}$ shows a slight increase in 2007 contrary to $\beta_{\text {Louch }}$

The first point was also reported by [38] when they analyzed the atmospheric turbidity levels at Taichung Harbor near Taiwan Strait. This was observed too by 
[24] when they studied the atmospheric turbidity for Hong Konghowed and showed that $\beta_{\text {Pinz }}>\beta_{\text {Louch }}$.

The second point is related to the city environment. The recent study of [39] showed that the urban aerosols during the same period of study predominate the other types of aerosols. It is explained by the presence of many companies of crusher plants and industrial companies installed around the city and agglomeration that increased from year to year.

The third point is probably related to the ozone layer thickness that presents a slight increased in 2007 as shown in Figure 10. Indeed, the ozone layer thickness decreased steadily from 2005 to 2008 but increased in 2007. $\beta_{\text {Gyem }}, \beta_{\text {modis }}$, $\beta_{D o g}$ and $\beta_{\text {Pinz }}$ seem to be more sensitive to ozone layer thickness than $\beta_{\text {Louch }}$.

Recurrent values of Angström turbidity coefficient and its cumulative frequency distribution were also analyzed during the period 2005-2008. The turbidity coefficient occurrence provides useful information about the site and its turbidity conditions. The cumulative frequency distribution is adapted to inform on the percentage of clear days where turbidity exceeds a given limit. Figure 11 plots the frequency distribution of $\beta_{\text {Dog }}, \beta_{\text {Louch }}, \beta_{\text {Pinz }}, \beta_{\text {Gyem }}$ and $\beta_{\text {modis }}$. We observe that the distribution is not Gaussian but looks like a Poisson law. We notice that the maximum recurrent value of:

1) $\beta_{\text {Dog }}$ is 0.03 with a frequency of about $10.5 \%$

2) $\beta_{\text {Louch }}$ is 0.07 with a frequency of about $8.3 \%$

3) $\beta_{\text {Pinz }}$ is 0.10 with a frequency of about $6.3 \%$

4) $\beta_{\text {Gyem }}$ is 0.09 with a frequency of $7.4 \%$

5) $\beta_{\text {modis }}$ is 0.02 with a frequency of about $9.9 \%$

The cumulative frequency distribution of Angström turbidity coefficient for each model is calculated and plotted in Figure 12. The various degrees of atmospheric clearness deduced from each cumulative frequency distribution [32] [38] are given in Table 4. We observe from the Table that $\beta_{D o g}$ and $\beta_{\text {modis }}$ yield the same and the maximum "clean to clear" conditions with respect to other methods. The minimum "clean to clear" conditions is yielded by $\beta_{\text {Pinz }}$ model. The maximum values for the "clean to turbid" conditions are yielded by $\beta_{\text {Pinz }}$ and $\beta_{\text {Gyem }}$ and the minimum by $\beta_{\text {modis }}$. $\beta_{\text {Dog }}$ yields the lowest values for "turbid to very turbid" conditions and both $\beta_{\text {Gyem }}$ and $\beta_{\text {Pinz }}$ models give the highest.

This analysis based on the cumulative frequency distribution confirms as before that Louche?s model gives a middle value of sky conditions in comparison with the other models. We will then consider its values as those for Ghardaïa and we may conclude that major sky conditions under cloudless days are between clean and turbid for this region.

\section{Conclusions}

The Angström turbidity coefficient $\beta$ is calculated with four broadband models using global solar irradiance measurements recorded during the period 


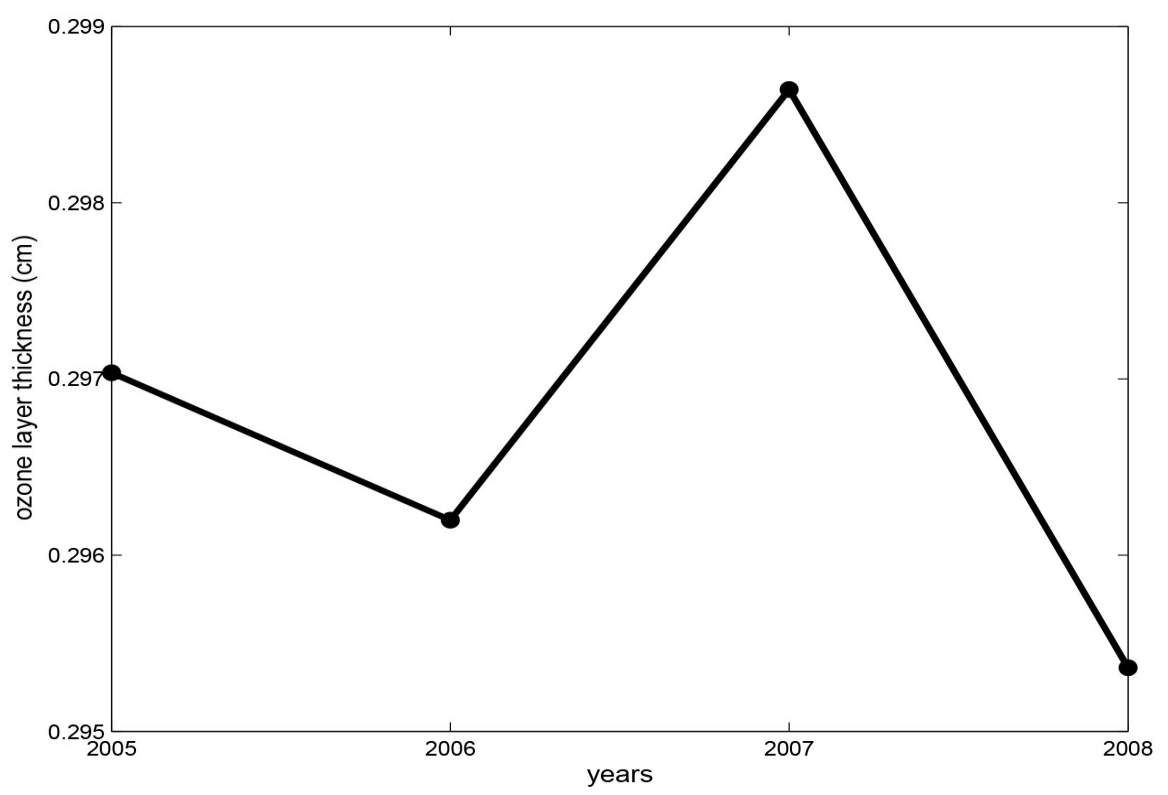

Figure 10. Annual average values of the ozone layer thickness for the period 2004-2008.

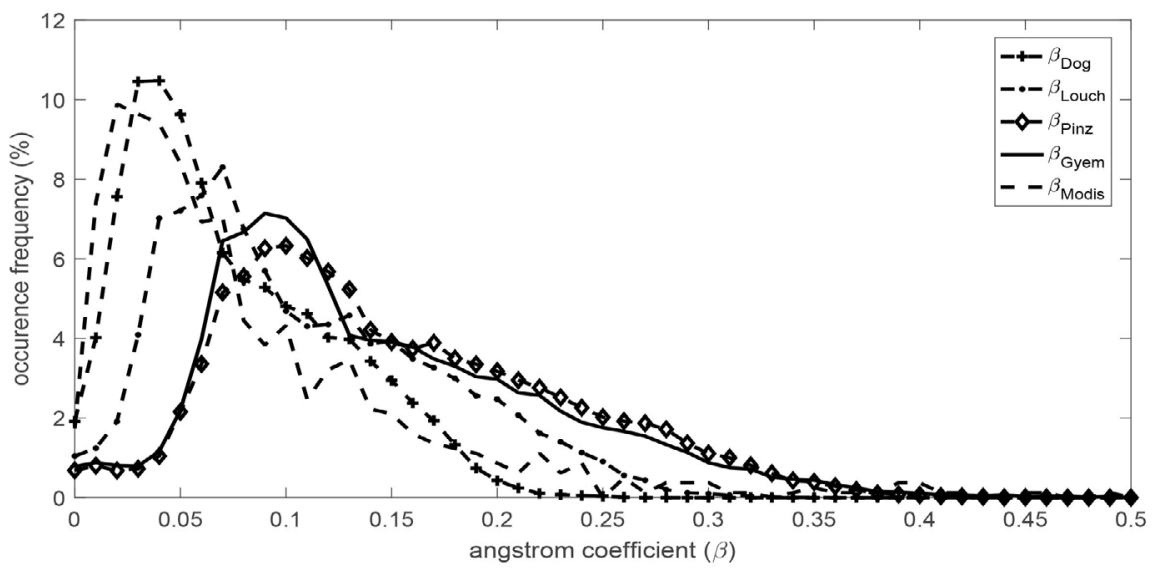

Figure 11. Frequency of occurrences for angstrom coefficient $\left(\beta_{\text {Pinz }}, \beta_{\text {Gyem }}, \beta_{\text {Louch }}\right.$, $\beta_{\text {modis }}, \quad \beta_{\text {Dog }}$, and $\beta_{\text {model }}$ ) measured between 2005 and 2008 .

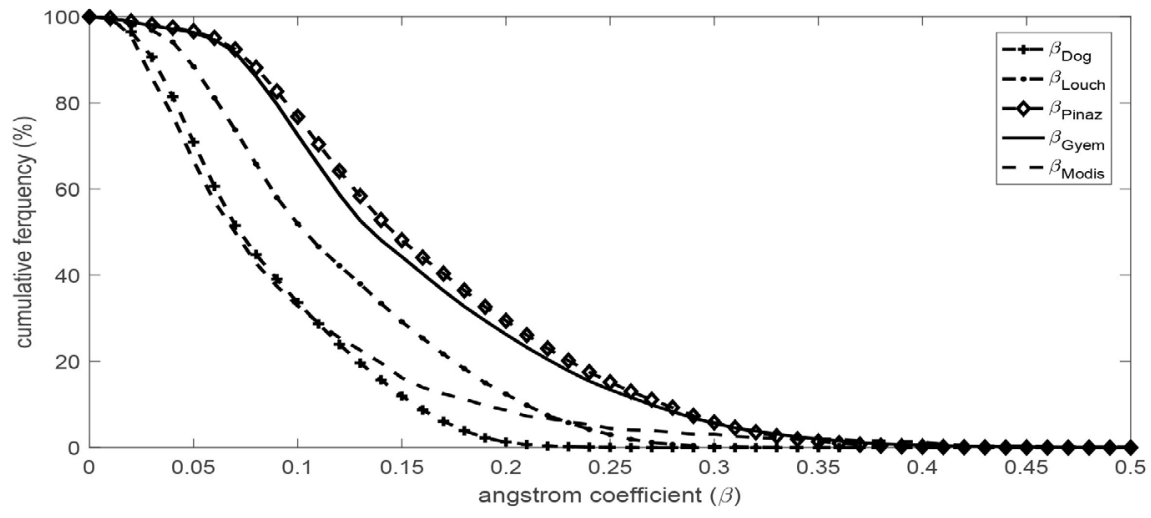

Figure 12. Cumulative frequency distribution for angstrom coefficient values ( $\beta_{\text {Pinz }}$, $\beta_{\text {Gyem }}, \beta_{\text {Louch }}, \beta_{\text {modis }}$ and $\beta_{\text {Dog }}$ ) obtained for the period 2005-2008. 
Table 4. Various degrees of atmospheric clearness.

\begin{tabular}{cccc}
\hline $\begin{array}{c}\beta \leq 0.1 \\
\text { (clean to clear) }\end{array}$ & $\begin{array}{c}0.1<\beta \leq 0.2 \\
\text { (clear to turbid) }\end{array}$ & $\begin{array}{c}\beta>0.2 \\
\text { (turbid to very turbid) }\end{array}$ \\
\hline$\beta_{\text {Pinz }}$ & $26 \%$ & $46 \%$ & $28 \%$ \\
$\beta_{\text {Gyem }}$ & $31 \%$ & $44 \%$ & $25 \%$ \\
$\beta_{\text {Louch }}$ & $51 \%$ & $38 \%$ & $11 \%$ \\
$\beta_{\text {Dog }}$ & $69 \%$ & $30 \%$ & $1 \%$ \\
$\beta_{\text {modis }}$ & $69 \%$ & $23 \%$ & $8 \%$ \\
\hline
\end{tabular}

2005-2008 at Ghardaïa in the south of Algeria. Data recorded with MODIS aboard Terra satellite (NASA) were also used. These models are referred to Dogniaux $\left(\beta_{\text {Dog }}\right)$, Louche $\left(\beta_{\text {Louch }}\right)$, Pinazo $\left(\beta_{\text {Pinz }}\right)$, Gueymard $\left(\beta_{\text {Gyem }}\right)$ and to MODIS $\beta_{\text {modis }}$. Results obtained from model calculations showed that $\beta_{\text {Gyem }}$ and $\beta_{\text {Pinz }}$ are very close as the couple $\beta_{\text {Dog }}$ and $\beta_{\text {modis }}$ while $\beta_{\text {Louch }}$ have middle values in regard to the other models. The differences between $\beta$ values are large and range from $50 \%$ to $100 \%$ between models.

All models and space data showed that the temporal variations of the Angström turbidity coefficients during 2005-2008 have the same trend. An increase of the annual mean values of $\beta$ was observed during this period, which is explained by the city environment and aerosols types. In addition, a slight increase of $\beta$ was observed in 2007 except for $\beta_{\text {Louch }}$. This jump was attributed to the ozone layer thickness leading to affirm that these models are sensitive to this atmospheric component.

We finally completed the comparison of the models by analyzing the occurrence and cumulative frequency distribution of the Angström turbidity coefficients. Results showed for all models that the frequency distribution is not Gaussian but looks like a Poisson law. The maximum recurrent values for $\beta_{D o g}$ is found near 0.03 , near 0.07 for $\beta_{\text {Louch }}$, near 0.10 for $\beta_{\text {Pinz }}$, near 0.09 for $\beta_{\text {Gyem }}$ and near 0.02 for $\beta_{\text {modis }}$. The cumulative frequency distribution study revealed also that $\beta_{\text {Dog }}$ and $\beta_{\text {modis }}$ yield the maximum "clean to clear conditions" with respect to the other models while $\beta_{\text {Pinz }}$ and $\beta_{\text {Gyem }}$ have the minimum. The opposite was observed on the same pairs of $\beta$ with regard to the "clear to turbid" and "turbid to very turbid" conditions. The Louche model gave middle values of sky conditions compared to the other models. This result leads us to consider Louche's model values for Ghardaïa city. The major sky conditions under cloudless days for this semi arid region are then between clean and turbid.

\section{Conflicts of Interest}

The authors declare no conflicts of interest regarding the publication of this paper.

\section{References}

[1] Djafer, D. and Irbah, A. (2013) Estimation of Atmospheric Turbidity over Ghardaia 
City. Atmospheric Research, 450, 46-51.

https://doi.org/10.1016/j.atmosres.2013.03.009

[2] Lopez, G. and Batlles, F.J. (2004) Estimate of the Atmospheric Turbidity from Three Broad-Band Solar Radiation Algorithms, a Comparative Study. Annales Geophysicae, 22, 2657-2668. https://doi.org/10.5194/angeo-22-2657-2004

[3] Angström, A. (1929) On the Atmospheric Transmission of Solar Radiation and on Dust in the Air. Geografiska Annaler, 2, 156-166. https://doi.org/10.2307/519399

[4] Angström, A. (1930) On the Atmospheric Transmission of Solar Radiation. Geografiska Annaler, 12, 130-159. https://doi.org/10.2307/519561

[5] Angström, A. (1961) Techniques of Determining the Turbidity of the Atmosphere. Tellus, 13, 214-223. https://doi.org/10.3402/tellusa.v13i2.9493

[6] Angström, A. (1964) The Parameters of Atmospheric Turbidity. Tellus, 16, 64-75. https://doi.org/10.3402/tellusa.v16i1.8885

[7] Dogniaux, R. (1974) Repréntations analytiques des composantes du rayonnement lumineux solaire. Conditions du ciel serein. Institut Royal de Métiorologie de Belgique, Serie A No. 83, 3-24.

[8] Louche, A., Peri, G. and Iqbal, M. (1986) An Analysis of Linke Turbidity Factor. Solar Energy, 37, 393-396. https://doi.org/10.1016/0038-092X(86)90028-9

[9] Pinazo, J.M., Canada, J. and Boscá, J.V. (1995) A New Method to Determine the Angström's Turbidity Coefficient: Its Application to Valencia. Solar Energy, 54, 219-226. https://doi.org/10.1016/0038-092X(94)00117-V

[10] Gueymard, C. and Vignola, F. (1998) Determination of Atmospheric Turbidity from the Diffuse-Beam Broadband Irradiance Ratio. Solar Energy, 63, 135-146. https://doi.org/10.1016/S0038-092X(98)00065-6

[11] Grenier, J. C., De La Casiniere, A. and Cabot, T. (1994) A Spectral Model of Linke's Turbidity Factor and Its Experimental Implications. Solar Energy, 52, 303-314. https://doi.org/10.1016/0038-092X(94)90137-6

[12] Kasten, F. (1980) A Simple Parameterization of the Pyrheliometric Formula for Determining the Linke Turbidity Factor. Meteorologische Rundschau, 33, 124-127.

[13] Kasten, F. (1996) The Linke Turbidity Factor Based on Improved Values of the Integral Ayleigh Optical Thickness. Solar Energy, 56, 239-244. https://doi.org/10.1016/0038-092X(95)00114-7

[14] Kasten, F. (1988) Elimination of the Virtual Diurnal Variation of the Linke Turbidity Factor. Meteor. Rdsch, 41, 93-94.

[15] Trabelsi, A. and Masmoudi, M. (2011) An Investigation of Atmospheric Turbidity over Kerkennah Island in Tunisia. Atmospheric Research, 101, 22-30. https://doi.org/10.1016/j.atmosres.2011.03.009

[16] Canada, J., Pinazo, J.M. and Boscá, J.V. (1993) Determination of Angström's Turbidity Coefficient at Valencia. Renewable Energy, 3, 621-626. https://doi.org/10.1016/0960-1481(93)90068-R

[17] Iqbal, M. (1983) An Introduction to Solar Radiation. Academic Press, Toronto.

[18] Machler, M.A. (1983) Parameterization of Solar Radiation under Clear Skies. M.Sc. Thesis, University of British Columbia, Vancouver.

[19] Machler, M.A. and Iqbal, M. (1985) A Modification of the ASHRAE Clear Sky Irradiation Model. ASHRAE Transactions, 91, 106-115.

[20] Louche, A., Maurel, M., Simonet, O., Peri, G. and Iqbal, M. (1987) Determination of Angström's Turbidity Coefficient from Direct Solar Irradiance Measurements. Solar 
Energy, 38, 89-96. https://doi.org/10.1016/0038-092X(87)90031-4

[21] Gueymard, C. (1995) SMARTS2, Simple Model of the Atmospheric Radiative Transfer of Sunshine: Algorithms and Performance Assessment. Rep. FSEC-PF-270-95, Florida Solar Energy Center. https://doi.org/10.1016/j.atmosres.2007.08.003

[22] Chaabane, M. (2008) Analysis of the Atmospheric Turbidity Levels at Two Tunisian Sites. Atmospheric Research, 87, 136-146.

[23] Chaiwiwatworakul, P. and Chirarattananon, S. (2004) An Investigation of Atmospheric Turbidity of Thai Sky. Energy and Buildings, 36, 650-659.

https://doi.org/10.1016/j.enbuild.2004.01.032

[24] Li, D.H.W. and Lam, J.C. (2002) A Study of Atmosphere Turbidity for Hong Kong. Renewable Energy, 25, 1-13. https://doi.org/10.1016/S0960-1481(01)00008-8

[25] Janjai, S., Kumharn, W. and Laksanaboonsong, J. (2003) Determination of Angstrom's Turbidity Coefficient over Thailand. Renewable Energy, 28, 1685-1700. https://doi.org/10.1016/S0960-1481(03)00010-7

[26] Karayel, M., Navvab, M., Ne'eman, E. and Selkowitz, S. (1984) Zenith Luminance and Sky Luminance Distributions for Daylighting Calculations. Energy and Buildings, 6, 283-291. https://doi.org/10.1016/0378-7788(84)90060-4

[27] Littlefair, P.J. (1994) The Luminance Distributions of Clear and Quasi-Clear Skies. Proceedings of the CIBSE National Lighting Conference, Cambridge, 267-283.

[28] Perez, R., Seals, R. and Michalsky, J. (1993) All-Weather Model for Sky Luminance Distribution-Preliminary Configuration and Validation. Solar Energy, 50, 235-245. https://doi.org/10.1016/0038-092X(93)90017-I

[29] Ichoku, C., Kaufman, Y.J., Remer, L.A. and Levy, R. (2004) Global Aerosol Remote Sensing from MODIS. Advances in Space Research, 34, 820-827. https://doi.org/10.1016/j.asr.2003.07.071

[30] Torres, O., Decae, R., Veefkind, P. and de Leeuw, G. (2002) OMI Aerosol Retrieval Algorithm. Algorithm Theoretical Baseline Document: Clouds, Aerosols, and Surface UV Irradiance. Vol. III, ATBD-OMI-03, Version 2.0.

[31] Wright, J., Perez, R. and Michalsky, J. (1989) Luminous Efficacy of Direct Irradiance: Variations with Insolation and Moisture Conditions. Solar Energy, 42, 387-394.

[32] Leckner, B. (1978) The Spectral Distribution of Solar Radiation at the Earth's Surface. Solar Energy, 20, 143-150. https://doi.org/10.1016/0038-092X(78)90187-1

[33] Gueymard, C. (1994) Analysis of Monthly Average Atmospheric Precipitable Water and Turbidity in Canada and Northern United States. Solar Energy, 53, 57-71. https://doi.org/10.1016/S0038-092X(94)90606-8

[34] Boscaa, J.V., Canada, J., Pinazo, J.M. and Ruiz, V. (1996) Angström's Turbidity Coefficient in Seville, Spain in the Years 1990 and 1991. International Journal of Ambiant Energy, 17, 171-178. https://doi.org/10.1080/01430750.1996.9675240

[35] Gueymard, C. (1989) A Two-Band Model for the Calculation of Clear Sky Solar Irradiance, Illuminance, and Photosynthetically Active Radiation at Earth's Surface. Solar Energy, 43, 253-265. https://doi.org/10.1016/0038-092X(89)90113-8

[36] Gueymard, C. (2012) Clear-Sky Irradiance Predictions for Solar Resource Mapping and Large-Scale Applications: Improved Validation Methodology and Detailed Performance Analysis of 18 Broadband Radiative Models. Solar Energy, 86, 2145 2169.

[37] Djafer, D., Irbah, A. and Zaiani, M. (2017) Identification of Clear Days from Solar Irradiance Observations Using a New Method Based on the Wavelet Transform. 
Renewable Energy, 101, 347-355. https://doi.org/10.1016/j.renene.2016.08.038

[38] Wen, C.C. and Yeh, H.H. (2009) Analysis of Atmospheric Turbidity Levels at Taichung Harbor near the Taiwan. Atmospheric Research, 94, 168-177.

https://doi.org/10.1016/j.atmosres.2009.05.010

[39] Zaiani, M., Djafer, D. and Chouireb, F. (2016) Classification of Aerosol Types over Ghardaia, Algeria, Based on MODIS Data. International Journal of Environmental Science and Development, 7, 745-749. 